\title{
Treatment of Basal Cell Carcinoma by Topical 25\% Podophyllin Solution
}

\author{
Khalifa E. Sharquie ${ }^{*}$, Adil A. Noaimi ${ }^{1}$, Mohammad S. Al-Zoubaidi ${ }^{2}$ \\ ${ }^{1}$ Department of Dermatology, College of Medicine, University of Baghdad Iraqi and Arabic Board of \\ Dermatology, Baghdad, Iraq \\ ${ }^{2}$ Department of Dermatology, Baghdad Teaching Hospital, Medical City, Iraq \\ Email: ${ }^{*}$ ksharquie@ymail.com, adilnoaimi@yahoo.com, mkhrabit@yahoo.com
}

Received 2 November 2014; accepted 28 August 2015; published 31 August 2015

Academic Editor: Reich Adam, Wroclaw Medical University, Poland

Copyright (C) 2015 by authors and Scientific Research Publishing Inc.

This work is licensed under the Creative Commons Attribution International License (CC BY).

http://creativecommons.org/licenses/by/4.0/

(c) (i) Open Access

\section{Abstract}

Background: Basal cell carcinoma is the most common malignancies of the skin. Numerous modalities of treatment are available. Podophyllin is an antimitotic and caustic agent that has been used in treatment of genital warts. Objective: To test the effectiveness and safety of topical $25 \%$ podophyllin in treatment of basal cell carcinoma. Patients and Methods: Thirty eight patients with basal cell carcinoma enrolled in this open labeled interventional study that had been enrolled in Department of Dermatology-Baghdad Teaching Hospital, Baghdad, from January 2010 to October 2011. History and physical examination was performed to all patients regarding all demographics detail related to the disease. Exclusion criteria: were pregnancy, recurrent tumors, aggressive deep subtypes, morpheaic type, and size more than $2 \mathrm{~cm}^{2}$ in diameter. Biopsies for all patients were done for histopathological examination at the first visit, and after clinical cure of the lesions. Lesions were treated with $25 \%$ topical podophyllin solution once weekly for 6 weeks. Follow up after clinical cured was done every 3 months up to 18 months to recording any sign and symptom of recurrent. Results: Thirty five patients with basal cell carcinoma completed the study: $28(80 \%)$ males and $7(20 \%)$ females with males to females ratio 4:1, their ages ranged from 30 - 87 (64.114 \pm 12.68) years, and the duration of the disease ranged from 2 months to 30 years $(6.88 . \pm 4.83)$ years. The size of lesions ranged from $0.8-1.9(1.454 \pm 0.239) \mathrm{cm}$. The total podophyllin applications number ranged from $2-6(4.65 \pm 1.055)$ sessions. The total numbers of treated lesions were 100 lesions: $64(64 \%)$ nodular, 31(31\%) pigmented, 3(3\%) Basosquamous, and $2(2 \%)$ superficial. Ninety six (96\%) lesions in 32 patients showed complete cure with 2 - 6 sessions, while 4 lesions in 3 patients showed partial response with 6 sessions. Biopsy from 21 cured lesions in 21 patients showed complete clearness apart from one with residual malignant cells. All the patients did not show clinical recurrence, during the follow up period up to 18 months. Inflammatory reactions were noted in all treated lesions as redness, edema and juicy skin 36 - 72 hours after topical po-

\footnotetext{
*Corresponding author.
}

How to cite this paper: Sharquie, K.E., Noaimi, A.A. and Al-Zoubaidi, M.S. (2015) Treatment of Basal Cell Carcinoma by Topical 25\% Podophyllin Solution. Journal of Cosmetics, Dermatological Sciences and Applications, 5, 189-197. 
dophyllin applications. After 3 - 5 days, the reaction became more exaggerated and ulceration developed, ended with crust formation. No evidence of systemic side effects was seen and this had been confirmed clinically and by laboratory during the sessions and one month later. Minimal or no scarring was noticed. Conclusions: Topical $25 \%$ podophyllin solution is a new, effective therapeutic modality in treatment of basal cell carcinoma which gives $96 \%$ cure, and it is highly recommended as alternative therapy in all type of basal cell carcinoma, single and multiple and for all ages especially for elderly patients and those who have surgeries phobia.

\title{
Keywords
}

\author{
BCC, Podophyllin, Topical Therapy
}

\section{Introduction}

Basal cell carcinoma (BCC) is the most common malignancy in worldwide [1], account for approximately $75 \%$ of all skin cancers [2]. It emerges from keratinocytes stem cells, in hair follicles, sebaceous glands, or interfollicular basal cells. Generally, most BCC cases are sporadic, but it may also appear in genetic disorders such as Goblin's syndrome and xeroderma pigmentosum [3] [4]. The majority of sporadic cases are induced by sunlight, specifically ultraviolet-B rays [5]. It commonly appears on the head and neck, or the back, but uncommon on the back of the hands and forearm. There is no known "precursor" lesion for basal cell carcinoma [6]. The incidence rate of this disease has been estimated to have increased between $20 \%-80 \%$ worldwide over the last three decades [1]. Mortality rate is low but basal cell carcinoma may occasionally grow aggressively causing extensive tissue destruction [2]. It is usually slowly growing and rarely metastasizing, and the metastatic potential rates are ranging from $0.0028 \%-0.1 \%$. The metastasis commonly occurs in the regional lymph nodes and lungs [7]. The major risk factor for BCC development is a patient's cumulative exposure to ultraviolet light [8].

There are many standard therapeutic modalities which have been used in treatment of basal cell carcinoma including surgical excision [9], curettage with electrodessication [10], cryotherapy [11], and radiotherapy [12]. Moh's micrographic surgery [13], photodynamic therapy (PDT) [14], laser therapy [15], intralesional interferon [16] and intralesional zinc sulphate 2\% [17]. Moreover, topical remedies such as Imiquimod [18], 5-flurouracil [18] and tazarotene [19] also have been used. However, many side effects were encountered with this medication [18] [19].

Podophyllin is the dried resin extracted from the roots and rhizomes of Podophyllum peltatum known as American mandrake, May apple, Ducks' foot and Indian apple. It is an antimitotic and caustic agent, a lipid-soluble compound with cytotoxic properties that easily cross cell membranes leads to inhibit cell mitosis and DNA synthesis by reversibly binding to tubulin; the protein subunit of the spindle microtubules thereby prevents polymerization of tubulin into microtubules; cell division is arrested and other cellular processes are impaired. It often causes local necrosis and death of tumor cells and erosion of the tissues. Podophyllin is indicated for the treatment of condyloma acuminatum (venereal warts), seborrhoeic, actinic, and roentgen ray keratoses; and juvenile papilloma of the larynx [20]-[25]. There is a local side effects associated with topical podophyllins such as erythema, tenderness, pruritus, burning, erosions, pain, and swelling [20] [26]. There are systemic side effects if extensive podophyllin treatment is used for large area, sub-dermal injection or ingestion [27] [28].

Accordingly, the aim of the present study is to use 25\% podophyllin as topical therapy for treatment of different types of basal cell carcinoma.

\section{Patients and Methods}

Thirty eight patients with basal cell carcinoma enrolled in this open, labeled interventional study had been enrolled in Department of Dermatology and Venereology-Baghdad Teaching Hospital, Baghdad, Iraq, from January 2010 - October 2011.

History was taken from each patient regarding to: age, gender, site, duration, smoking, and alcohol intake. Close clinical examination was done for each patient. Skin photo-type was established for all patients according to Fitzpatrick's classification and any signs of sun damage were recorded. Basal cell carcinoma lesions were as- 
sessed including their numbers, site, morphology, size, color and lymph nodes examination was performed to all patients. Exclusion criteria: were pregnancy, recurrent tumors and those with more aggressive subtypes, morpheaic type of BCC, and size more than $2 \mathrm{~cm}^{2}$ in diameter. Shave or incision biopsies were done for clinical and histopathological examination for all patients at the first visit, and after clinical cure of the lesions.

Formal consent was taken before the start the therapy, after full explanation about the nature of the disease, course, the procedure of treatment, follow up, prognosis and the need for pre and post treatment photographs. Also, ethical approval was performed by the Scientific Council of Dermatology and Venereology-Iraqi Board for Medical Specializations. Digital photographs were taken using SONY Cyber-Shot T300 10.1 MP for each patient in good illumination.

The lesions treated with 25\% topical podophyllin solution once weekly for 6 weeks. And the follow up was done after clinical cure every 3 months up to 18 months to record recurrence rate of the lesions after clinical cured.

\subsection{Preparation of Topical 25\% Podophyllin Solution and the Way of Use}

Podophyllum Resin 25\% Topical Solution USP prepared by mixing 25 grams of the alcohol-soluble extract of podophyllum resin in alcohol and 10 grams of the alcohol-soluble extract of benzoin in alcohol, and diluting with alcohol to make $100 \mathrm{ml}$ The solution was applied by a wood stick applicator and the lesion was covered with thin layer of solution. The amounts used in each session depend on the size of lesion but always not exceeding $0.5 \mathrm{ml}$. The solution was allowed to dry in approximately 3 minutes and patients were instructed to wash off it after 5 hours. The solution was applied once weekly for maximum of 6 weeks and the number of applications depend on rate of response of the lesions [20].

\subsection{Statistical Descriptive}

1) Excel program has been used for the statistical analysis.

2) Mean, standard deviation, and percentage of the treated cases calculated to show the values of the results.

3) Table and figure has been used to present the results.

\section{Results}

Thirty five patients with basal cell carcinoma completed the study: 28 (80\%) males and 7 (20\%) females with males to females ratio 4:1, their ages ranged from 30 - 87 (64.114 \pm 12.68$)$ years, and the duration of the disease ranged from 2 months to 30 years (6.88. \pm 4.83$)$ years. The size of lesions ranged from $0.8-1.9 \mathrm{~cm}(1.454 \pm$ $0.239) \mathrm{cm}$. The total podophyllin applications number ranged from $2-6(4.65 \pm 1.055)$ sessions. The total numbers of treated lesions were 100 lesions: 64 (64\%) nodular, 31 (31\%) pigmented (Figures 1-7), 3 (3\%) Basosquamous (Figure 8), and 2 (2\%) superficial.

Ninety six (96\%) lesions in 32 patients showed complete clinical cure with 2 - 6 (4.65 \pm 1.055$)$ sessions. while 4 lesions in 3 patients showed partial response with 6 sessions. Biopsy from 21 lesions in 21 patients showed complete clearness apart from one with residual malignant cells (4.76\%). All the patients did not showed any clinical recurrence, up to 18 months.

Inflammatory reaction was noted in all treated lesions as redness, edema and juicy skin 36 - 72 hours after topical podophyllin. After 3 - 5 days, the reaction became more exaggerated and ulceration developed, ended with crust formation.

No evidence of systemic side effects was seen, and this had been confirmed clinically and by laboratory during the sessions and 1 months later.

Although all lesions recovered completely after podophyllin application, but we noticed that different types of BCC might respond differently as superficial and ulcerative BCC responded more quickly within $4.5 \pm 1.09$ sessions (Figure 6 and Figure 7), while the nodular type needed much longer time and more application in order to achieve full cure and usually with $5.15 \pm 0.812$ sessions (Figures 1-5, Figure 8 and Figure 9).

Regarding the side effects, no evidence of systemic side effects was found in any of these cases, and this had been confirmed by clinical examination and laboratory results including blood picture, liver, and renal function tests. Minimal or no scarring was noticed in all lesions but postinflammatory hyperpigmentation was observed in 3 cases and one patient developed transient hypopigmentation. But generally this therapy gave nice cosmetic result. 


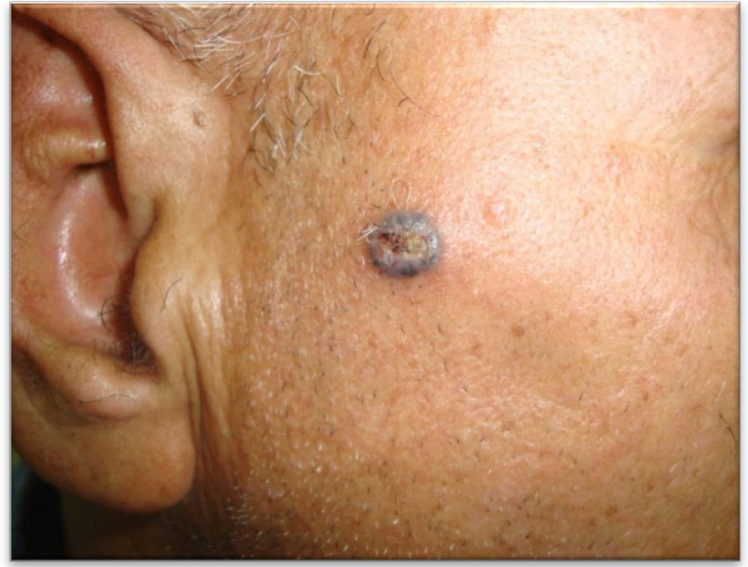

(a)

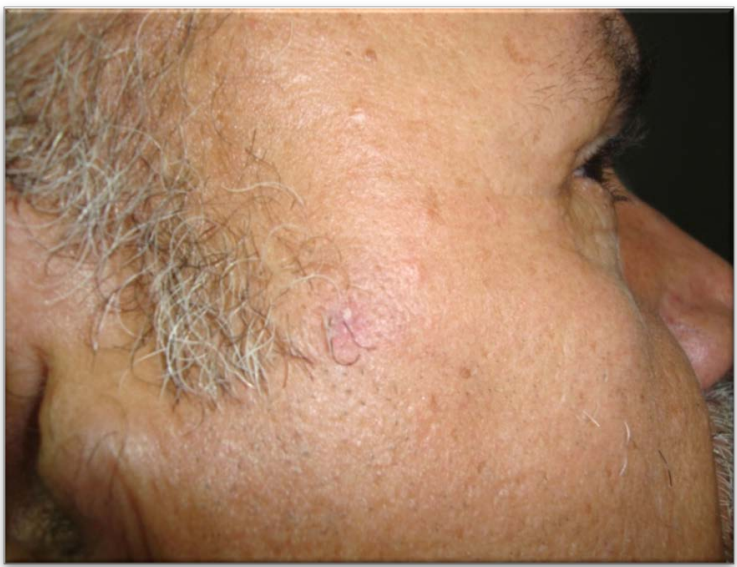

(b)

Figure 1. (a) Pigmento-nodular BCC before treatment with podophyllin, (b) the same lesion above after podophyllin application, after 4 sessions.

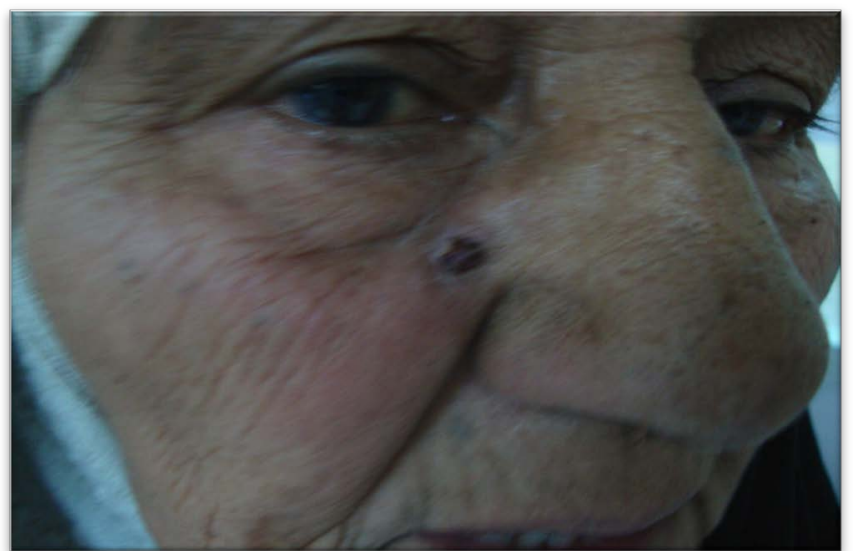

(a)

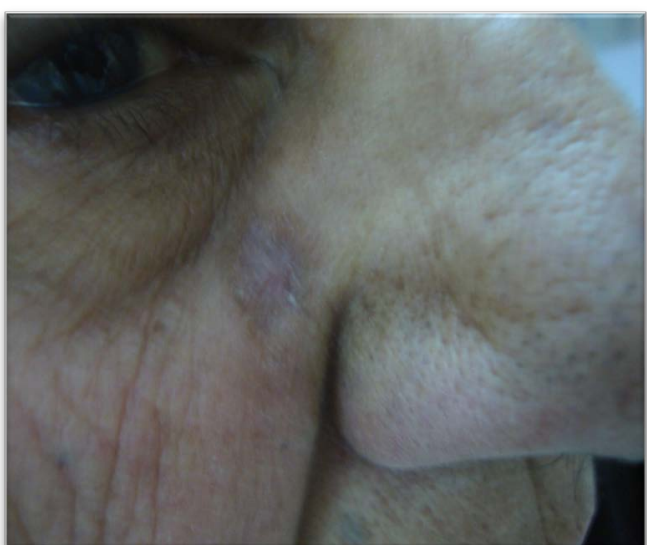

(b)

Figure 2. (a) Nodulopigmented BCC on the nasolabal fold, (b) the same patient with full clinical cure after podophyllin application, after 5 sessions.

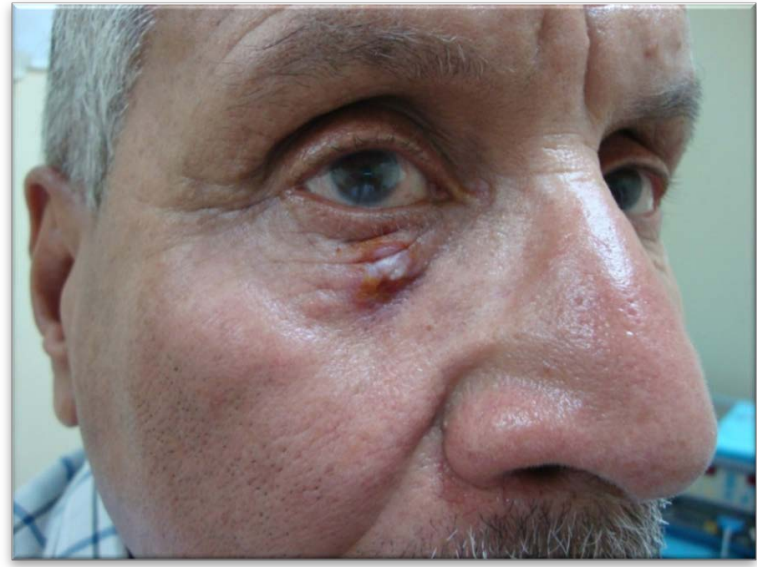

(a)

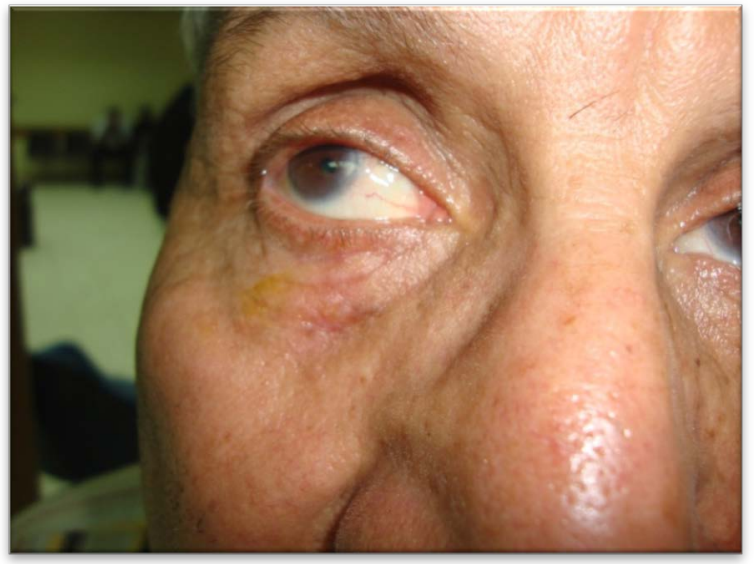

(b)

Figure 3. (a) Showing 65 years old patient with nodular BCC near eye lid before podophyllin application, (b) the same patient above after podophyllin application. After 5 sessions. 


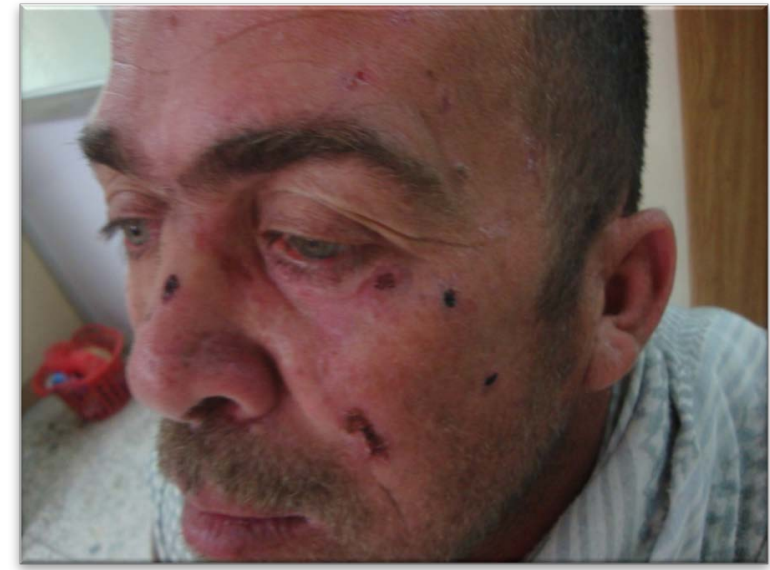

(a)

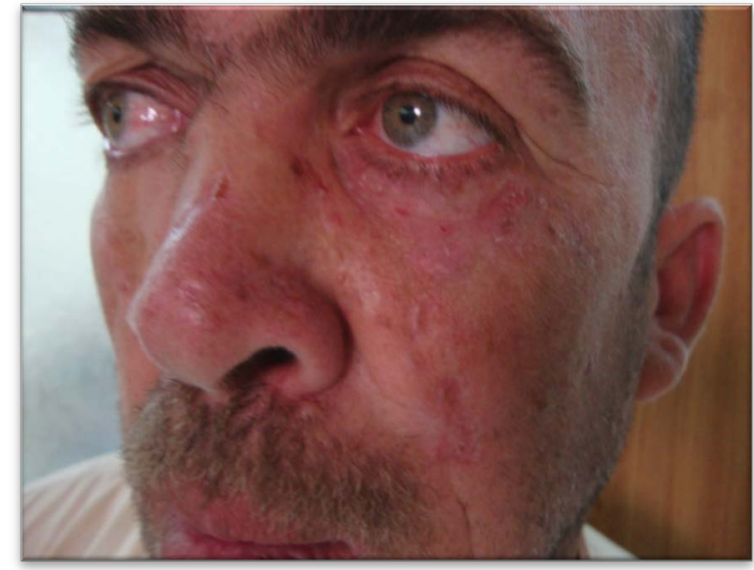

(b)

Figure 4. (a) Showing 30 years old male presenting with Gorlin's syndrome and multiple BCC before podophyllin application, (b) the same patient with Gorlin's syndrome after 6 sessions of podophyllin application.

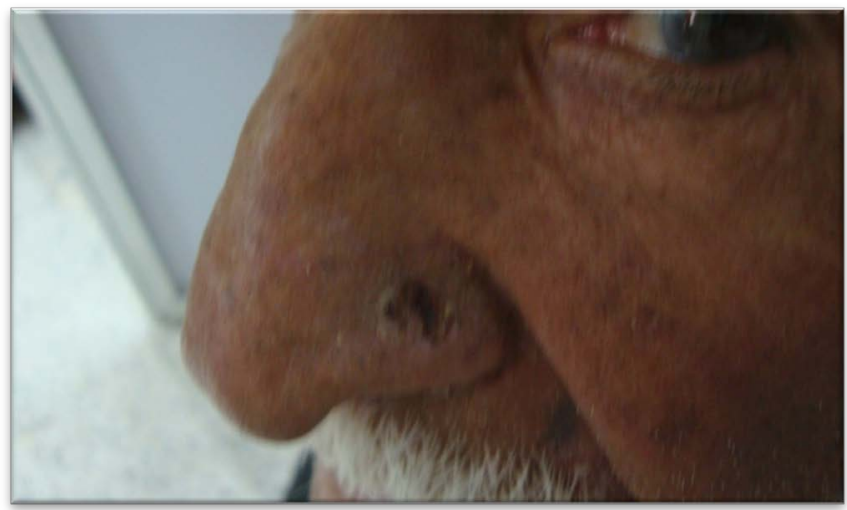

(a)

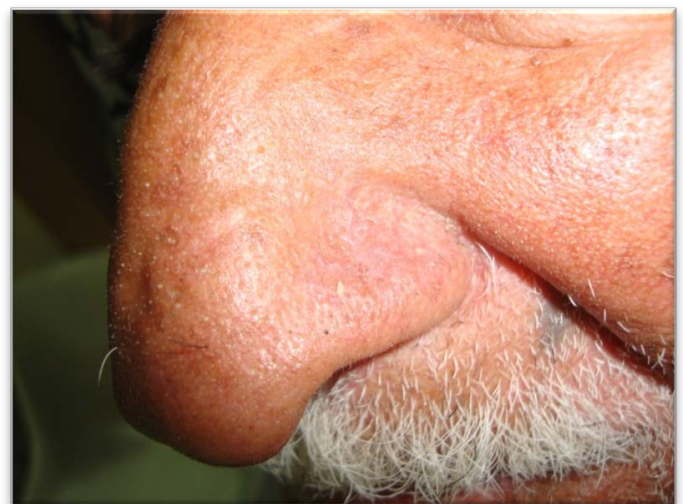

(b)

Figure 5. (a) A 75 years old male showing nodular BCC on ala nasi before podophyllin application, (b) the same patient above after 4 session of podophyllin application.

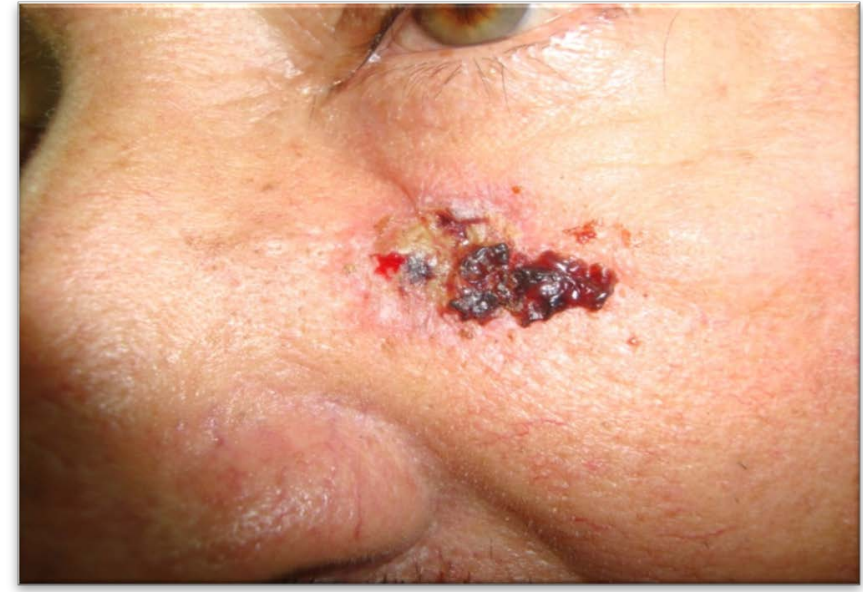

(a)

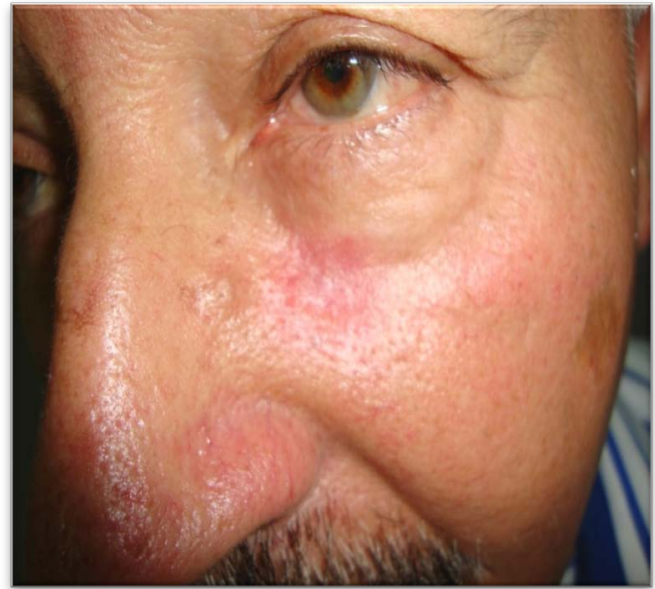

(b)

Figure 6. (a) Showing ulcerative BCC on face before treatment with topical podophyllin, (b) the same patient above after podophyllin application. After 4 sessions. 


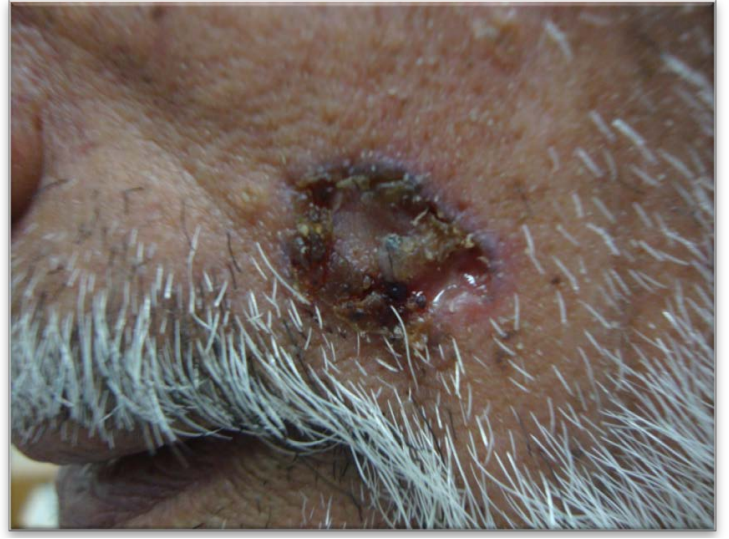

(a)

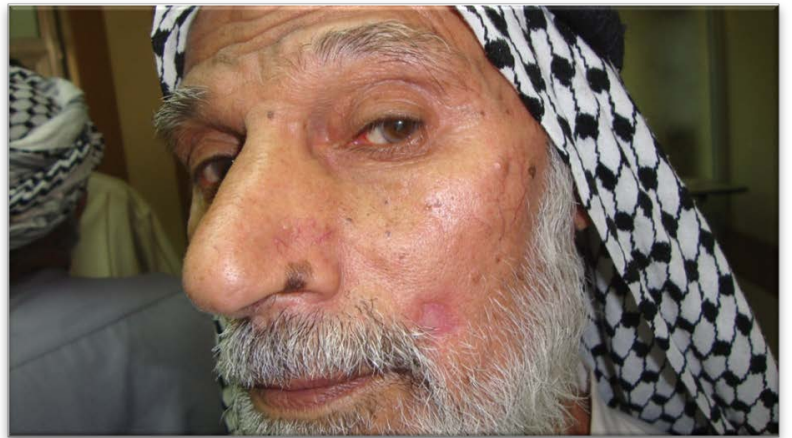

(b)

Figure 7. (a) Noduloulcerative BCC nasolabial before podophyllin application, (b) the same patient after podophyllin application. After 4 sessions.

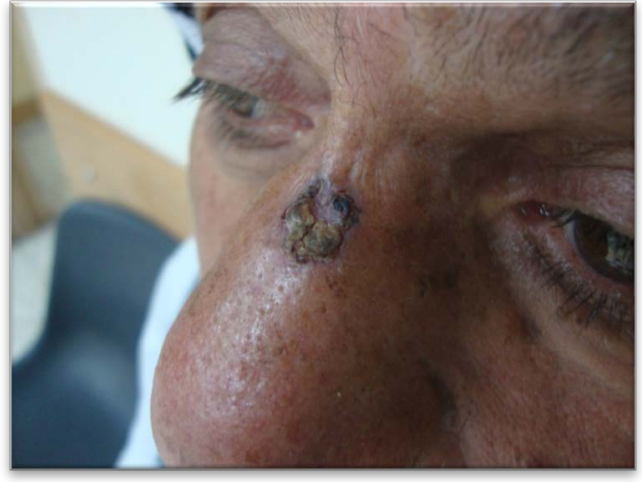

(a)

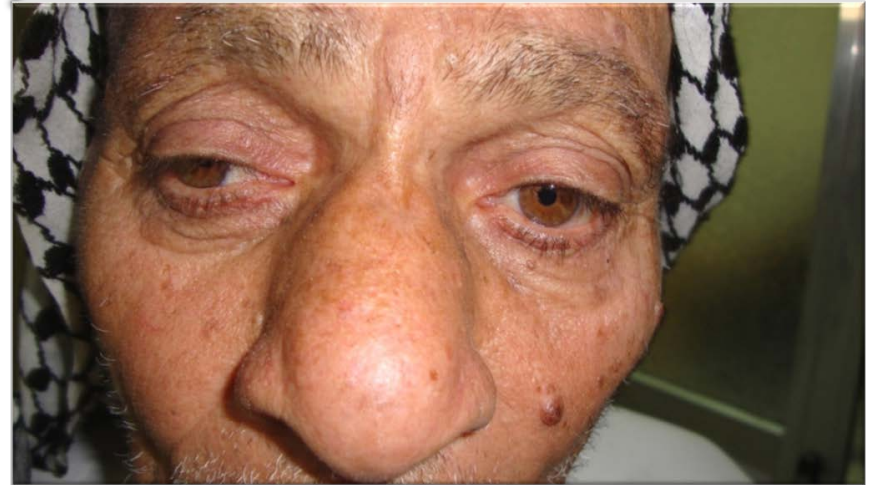

(b)

Figure 8. (a) Showing patient with Basosquamous cell carcinoma on the nose before treatment with podophyllin, (b) the same patient showing a full cure after with podophyllin application. After 6 sessions treatment.

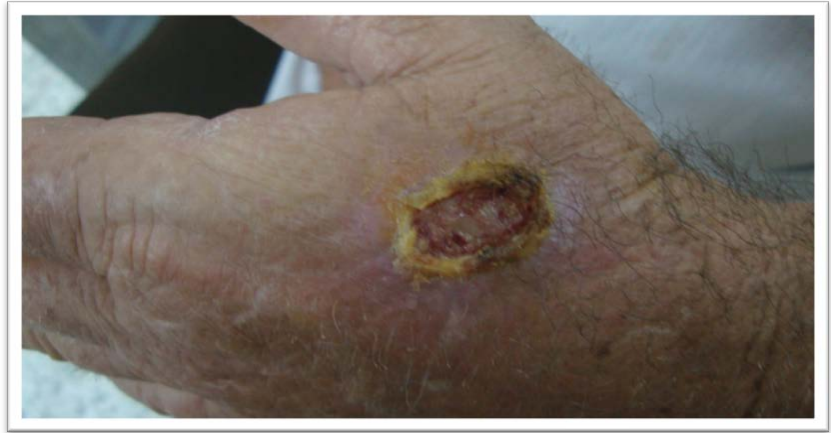

(a)

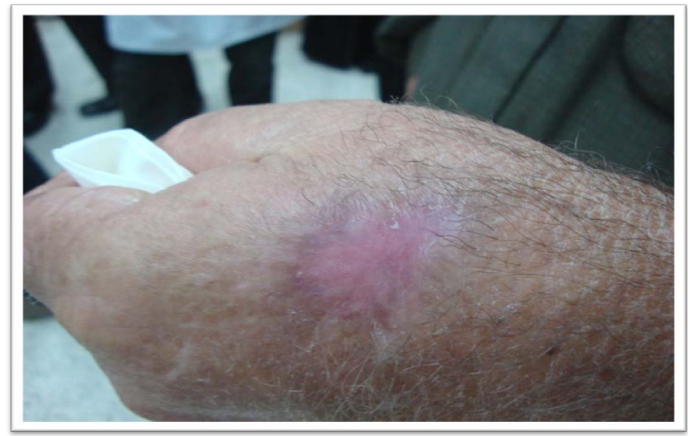

(b)

Figure 9. (a) BCC on dorsum of the left hand before podophyllin application, (b) the same patient showing a full cure after podophyllin application after 5 sessions.

\section{Discussion}

There are controversies whether to use surgical or non surgical therapy for basal cell carcinoma but the clinicians always search for simple, non costly, easy procedure in order to achieve cure. There are many standard therapeutic modalities used in treatment of BCC including surgical excision [9], curettage with electrodessica- 
tion [10], cryotherapy [11], and radiotherapy [12]. Moh’s micrographic surgery [13], photodynamic therapy (PDT) [14], laser therapy [15], intralesional interferon [16], and intralesional zinc sulphate 2\% [17]. Moreover topical remedies such as Imiquimod [18], 5-flurouracil [18], tazarotene [19], also have been used. However many side effects were encountered with this medication [18] [19].

Topical Imiquimod is approved by food and drug administration (FDA) only for superficial BCCs as large as $2 \mathrm{~cm}$ in diameter located on the neck, trunk, or extremities. Cure rates for nonaggressive subtypes of BCC have ranged from $60 \%$ - 100\% [29] [30]. Local side effects include erythema, hardened skin, edema, and vesiculation, and erosion, ulceration, scabbing, and flaking. It can have systemic effects such as headache, gastrointestinal disturbances, nausea, and vomiting. Therefore, topical 5\% Imiquimod cream applied once daily 5 days per week for at least 6 weeks [31] [32].

Topical 5-FU is usually used in cases of low-risk BCCs especially superficial BCCs. 5-FU can be used for multiple BCCs on the trunk and extremities, but it is not indicated for nodular BCCs. However, this compound is not strong enough to eliminate tumors with extensive invasion or involving a patient' follicles [33] [34]. It can cure up to $95 \%$ of superficial BCCs [15]. Solution and cream formulations of 5\% 5-FU application twice daily for at least 6 weeks, for superficial BCCs, However , therapy may be required for as long as 10 to 12 weeks [31].

Tazarotene has been preliminarily shown to be efficacious in the regression of small superficial and nodular BCC when applied topically in $0.1 \%$ gel formulation over a range of 6 weeks to 8 months, with one study reporting complete regression without recurrence to be $30.5 \%$ at 3-year follow-up [19].

The present work is the first well established extensive study to be reported as it is showed $96 \%$ cure and it is a superior when compared with other topical therapies like Imiquimod, 5-FU, and tazarotene as gave a high cure rates, no relapse, recovery with short time, no post treatment scarring and no systemic and minimal topical side effects.

Topical 25\% podophyllin solution had been used in treatment of superficial, nodular, ulcerative, pigmented BCCs in head, neck, and all over the body, for the single and multiples BCCs in sporadic and genodermatosis one, with diameter equal or less than $2 \mathrm{~cm}^{2}$. All the lesions of BCC that treated with topical podophyllin has been cured by 2 to 6 session with cure rates 96\%. The side effects that had seen in this work are local side effects and as follow: erythema, edema, ulceration, with or without slight pain following by crust formation. No systemic toxicity has been shown.

Cure rate in the present study was $96 \%$ which is high, in comparison with other topical therapeutic modalities used in the treatment of basal cell carcinoma: as the treatment for nonaggressive subtypes of BCC with topical Imiquimod 5\% cream have cure rates ranged from $60 \%$ to $100 \%$, and this topical medication is approved by FDA only for superficial BCCs as large as $2 \mathrm{~cm}$ in diameter located on the neck, trunk, or extremities [29] [30]. while we using the topical podophyllin in all areas of the head, face, the neck, trunk, and the extremities. In addition Imiquimod need more application and it is costly in comparison to the podophyllin. The comparison the topical 5-FU in treatment BCC with topical podophyllin, we found that the topical 5-FU is usually used in cases of low-risk BCCs specially superficial BCCs [33], and it can be used for multiple BCCs on trunk and extremities, but it not indicated for nodular BCC [34]. It can cure up to 95\% of superficial BCC, and therapy may be required for as long as 6 to 10 weeks [15], while we using the topical podophyllin for superficial and nodular BCC in high and low-risk areas and for 6 weeks once weekly. Topical podophyllin has fewer side effects than topical Imiquimod and 5-FU. Topical podophyllin is much superior to Imiquimod and 5-FU.and the side effects of podophyllin is could be considered as part of mechanism of action as unless there is a reaction, there will be not cure. Accordingly these are not side effects.

\section{Conclusion}

Topical 25\% podophyllin solution is a new, effective therapeutic modality in treatment of basal cell carcinoma which gives $96 \%$ cure in all varieties of basal cell carcinoma. It is highly recommended for any age and any type of basal cell carcinoma but especially for elderly patients and those who have surgeries phobia.

\section{References}

[1] Mikilineni, R. and Weinstock, M.A. (2001) Epidemiology of Skin Cancer. In: Atlas of Clinical Oncology: Skin Cancer, BC Decker, London, 1-15. 
[2] Akinci, M., Aslan, S., Morkoc, F. and Cetin, A. (2008) Metastatic Basal Cell Carcinoma. Acta Chirurgica Belgica, 108, 269-272.

[3] Lacour, J.P. (2002) Carcinogenesis of Basal Cell Carcinoma: Genetics and Molecular Mechanism. British Journal of Dermatology, 146, 17-19. http://dx.doi.org/10.1046/j.1365-2133.146.s61.5.x

[4] Kogerman, P., Krause, D. and Rahnama, F. (2002) Alternative First Exons of PTCH1 Are Differentially Regulated in Vivo and May Confer Different Functions to the PTCH1 Protein. Oncogene, 21, 6007-6016. http://dx.doi.org/10.1038/sj.onc.1205865

[5] Kim, M., Park, H.J. and Baek, S. (2002) Mutations of the P53 and PTCH Gene in Basal Cell Carcinoma: UV Mutation Signature and Strand Bias. Journal of Dermatological Science, 29, 1-6.

[6] Nouri, K., Christopher, J., Ballard, B.S., Asha R., Patel, B.S. and Brasie, R.A. (2008) Basal Cell Carcinoma. Skin Cancer, The McGraw-Hill Companies.

[7] Ting, P.T., Kasper, R. and Arlette, J.P. (2005) Metastatic Basal Cell Carcinoma: Report of Two Cases and Literature Review. Journal of Cutaneous Medicine and Surgery, 9, 10-15.

[8] Hoban, P.R., Ramachandran, S. and Strange, R.C. (2002) Environment, Phenotype and Genetics: Risk Factors Associated with BCC of the Skin. Expert Review of Anticancer Therapy, 2, 570-579. http://dx.doi.org/10.1586/14737140.2.5.570

[9] Grabski, W.J. and Salasche, S.J. (1998) Positive Surgical Excision Margins of A Basal Cell Carcinoma. Dermatologic Surgery, 24, 921-924. http://dx.doi.org/10.1111/j.1524-4725.1998.tb04276.x

[10] Nouri, K., Spencer, J. and Taylor, J. (1999) Does Wound Healing Contribute to the Eradication of Basal Cell Carcinoma Following Curettage and Electrodessication? Dermatologic Surgery, 25, 183. http://dx.doi.org/10.1046/j.1524-4725.1999.08128.x

[11] Kaur, S., Thami, G.P. and Kanwar, A.J. (2003) Basal Cell Carcinoma-Treatment with Cryosurgery. Indian Journal of Dermatology, Venereology and Leprology, 69, 188-190.

[12] Mendenhall, W.M., Amdur, R.J., Hinerman, R.W., Cognetta, A.B. and Mendenhall, N.P. (2009) Radiotherapy for Cutaneous Squamous and Basal Cell Carcinomas of the Head and Neck. The Laryngoscope, 119, 1994-1999. http://dx.doi.org/10.1002/lary.20608

[13] Tierney, E.P. and Hanke, C.W. (2009) Cost Effectiveness of Mohs Micrographic Surgery: Review of the Literature. Journal of Drugs in Dermatology, 8, 914-922.

[14] Foley, P. (2005) Clinical Efficacy of Methyl Aminolevulinate Photodynamic Therapy in Basal Cell Carcinoma and Solar Keratosis. Australasian Journal of Dermatology, 46, S8-S10.

[15] Padgett, J.K. and Hendrix, J.D. (2001) Cutaneous Malignancies and Their Management. Otolaryngologic Clinics of North America, 34, 523-553. http://dx.doi.org/10.1016/S0030-6665(05)70004-9

[16] Kim, K.H., Yavel, R.M. and Gross, V.L. (2004) Intralesional Interferon Alpha-2b in the Treatment of Basal Cell Carcinoma and Squamous Cell Carcinoma: Revisited. Dermatologic Surgery, 30, 116-120.

[17] Sharquie, K.E., Al-Nuaimy, A.A. and Al-Shmary, F.A. (2005) New Intralesional Therapy for Basal Cell Carcinoma by 2\% Zinc Sulphate Solution. Saudi Medical Journal, 26, 359-361.

[18] Love, W.E., Bernhard, J.D. and Bordeaux, J.S. (2009) Topical Imiquimod or Fluorouracil Therapy for Basal and Squamous Cell Carcinoma: A Systematic Review. Archives of Dermatology, 145, 1431-1438. http://dx.doi.org/10.1001/archdermatol.2009.291

[19] Bianchi, L., Orlandi, A., Campione, E., Angeloni, C., Costanzo, A. and Spagnoli, L.G. (2004) Topical Treatment of Basal Cell Carcinoma with Tazarotene: A Clinicopathological Study on a Large Series of Cases. British Journal of Dermatology, 151, 148-156. http://dx.doi.org/10.1111/j.1365-2133.2004.06044.X

[20] United State Pharmacopeia Committees (Eds.) (2004) Podophyllin. In: United State Pharmacopeia Committees, Eds., Drug Information for the Health Care Professional, 24th Edition, Rev. US Convention Inc., Thomason Micromedex, 2341-2348.

[21] Podophyllum (Topical). Drugs.com. Know More Be Sure. Update 3 August 2000. http://www.drugs.com/mmx/podocon-25.html

[22] Katzung, B.G. (1992) Basic and Clinical Pharmacology. 5th Edition, Appleton and Lange, Norwalk, 884.

[23] Martin, E.C., Christy, L., Cowan, M.C., Marshal, S.W., Dawson, A.H., Seifert, S.A., Schon, W.S., Yip, L., Keyes, D.C., Hurlbut, K.M. and Erdman Arm Dart, R.C. (Eds). (2004) Medical Toxicology. 3rd Edition, Chap. 255, Walters Kluwer Company, Philadelphia, 1690-1691.

[24] Lin, M.C., Cheng, H.W., Tsai, Y.C., Liao, P.L. and Kang, J.J. (2009) Podophyllin Induced Genotoxicity in Vitro and in Vivo through ROS Production. Drug and Chemical Toxicology, 32, 68-76. 
http://dx.doi.org/10.1080/01480540802433757

[25] Rahman, A.U., Ashraf, M., Choudhary, M.I., Rehman, H.U. and Kazmi, M.H. (1995) Antifungal Aryltetralin Lignans from Leaves of Podophyllum hexandrum. Phytochemistry, 40, 427-431. http://dx.doi.org/10.1016/0031-9422(95)00195-D

[26] Beutner, K.R. and Ferenczy, A. (1997) Therapeutic Approaches to Genital Warts. The American Journal of Medicine, 102, 28-37. http://dx.doi.org/10.1016/S0002-9343(97)00181-2

[27] Moore, M.M. and Strober, B.E. (2008) Topical and Intralesional Cytotoxic Agent. In: Wolff, K., Goldsmith, L.A., Katz, S.I., Gilchrest, B.A., Paller, A.S. and Leffell, D.J., Eds., Fitzpatrick’s Dermatology in General Medicine, 7th Edition, Chap. 220, McGraw-Hill-Company, New York, 2124.

[28] Habif, T.P. (2004) Sexually Transmitted Viral Infection. In: Habif, T.P., Ed., Clinical Dermatology, 4th Edition, Chap. 11, Mosby Inc., Toronto, 336-342.

[29] Huber, A., Huber, J.D. and Skinner, R.B. (2004) Topical Imiquimod Treatment for Nodular Basal Cell Carcinomas: An Open-Label Series. Dermatologic Surgery, 30, 429-430. http://dx.doi.org/10.1097/00042728-200403000-00023

[30] Vidal, D., Matias-Guiu, X. and Alomar, A. (2004) Open Study of the Efficacy and Mechanism of Action of Topical Imiquimod in Basal Cell Carcinoma. Clinical and Experimental Dermatology, 29, 518-525.

http://dx.doi.org/10.1111/j.1365-2230.2004.01601.x

[31] Efudex (Fluorouracil) Topical Solution and Cream (Product Pamphlet). ICN Pharmaceuticals, Inc., Costa Mesa, 2000.

[32] Berman, B., Sullivan, T. and De Araujo, T. (2003) Expression of Fas-Receptor on Basal Cell Carcinomas after Treatment with Imiquimod 5\% Cream or Vehicle. British Journal of Dermatology, 149, 59-61. http://dx.doi.org/10.1046/j.0366-077X.2003.05634.x

[33] Lawrence, C.M. (1999) Mohs Micrographic Surgery for Basal Cell Carcinoma. Clinical and Experimental Dermatology, 24, 130-133. http://dx.doi.org/10.1046/j.1365-2230.1999.00433.x

[34] Reymann, F. (1979) Treatment of Basal Cell Carcinoma of the Skin with 5-Fluorouracil Ointment. Dermatologica, 158, 368-372. http://dx.doi.org/10.1159/000250782 